\title{
RESEARCH
}

Open Access

\section{Trends of Mycobacterium tuberculosis and rifampicin resistance in Adigrat General Hospital, Eastern zone of Tigrai, North Ethiopia}

\author{
Getachew Kahsu Abay ${ }^{1 *}$ (1) and Bahlbi Hailay Abraha
}

\begin{abstract}
Background: Tuberculosis is an infectious disease usually caused by Mycobacterium tuberculosis bacteria. The global emergence of mono- or multidrug-resistant tuberculosis and extensively drug-resistant forms of tuberculosis pose a considerable challenge to tuberculosis control programs. There has been no reliable and organized data on trends and drug resistance of Mycobacterium tuberculosis in the study area. Therefore, this study aimed to determine the trends of Mycobacterium tuberculosis and rifampicin resistance in the Adigrat General Hospital, eastern Zone of Tigrai, North Ethiopia.
\end{abstract}

Methods: A hospital-based retrospective cross-sectional study was conducted at Adigrat General Hospital from January 2015 to 2018. Data was collected retrospectively from the GeneXpert ${ }^{\text {TM }}$ TB registration book using a data extraction format. Data was entered into Epi-Info 3.1 and subsequently exported and analyzed using SPSS Version 20.The results were summarized using descriptive statistics, tables, and figures. Bivariate and multi-variant regression analysis was employed to measure the association between dependent and independent variables. $P$ values $<0.05$ were considered statistically significant.

Result: A total of 5944 Mycobacterium tuberculosis presumptive patients were included in the study. The majority of the study participants were male (58.1\%) with participants' median age of 40.0 (IQR 26-57) years, the majority were 3044 years. The overall positive cases of Mycobacterium tuberculosis was $24.3 \%$ (1446) with a total of $132(9.1 \%)$ found to be resistant to rifampicin. Of the total confirmed positive cases 8.7\% (103/1188) and 11.2\% (29/258) were rifampicin resistance of presumptive tuberculosis and presumptive drug resistance tuberculosis patients respectively. Age, the reason for diagnosis, site of presumptive tuberculosis, and/or being HIV infected showed significant association with our dependent variable; however, only age and being HIV infected were associated with rifampicin resistance.

Conclusion: In our study, the overall trends of Mycobacterium tuberculosis and rifampicin resistance were found to be high. Rifampicin resistance is more common in patients with HIV and presumptive drug resistance tuberculosis individuals. Therefore, maximizing early detection of drug-resistant and strengthening tuberculosis infection control activities are recommended to reduce the burden of this contagious and potentially deadly disease.

Keywords: Adigrat general hospital, Rifampicin-resistant, Mycobacterium tuberculosis, Tigrai, Ethiopia

\footnotetext{
*Correspondence: getakahsu2004@gmail.com; getakahsu@yahoo.com

'Department of Medical Laboratory, College of Medicine and Health

Sciences, Adigrat University, P. O. Box 50, Adigrat, Ethiopia

Full list of author information is available at the end of the article
}

\section{$\triangle B M C$}

(c) The Author(s). 2020 Open Access This article is licensed under a Creative Commons Attribution 4.0 International License, which permits use, sharing, adaptation, distribution and reproduction in any medium or format, as long as you give appropriate credit to the original author(s) and the source, provide a link to the Creative Commons licence, and indicate if changes were made. The images or other third party material in this article are included in the article's Creative Commons licence, unless indicated otherwise in a credit line to the material. If material is not included in the article's Creative Commons licence and your intended use is not permitted by statutory regulation or exceeds the permitted use, you will need to obtain permission directly from the copyright holder. To view a copy of this licence, visit http://creativecommons.org/licenses/by/4.0/ The Creative Commons Public Domain Dedication waiver (http://creativecommons.org/publicdomain/zero/1.0/) applies to the data made available in this article, unless otherwise stated in a credit line to the data. 


\section{Introduction}

Tuberculosis (TB) is caused by a bacterium called Mycobacterium tuberculosis. The bacteria usually attack the lungs, but TB bacteria can attack any part of the body, such as the kidney, spine, and brain. Not everyone infected with TB bacteria becomes sick. As a result, two TB-related conditions exist: latent TB infection (LTBI) and TB disease. If not treated properly, TB disease can be fatal. Tuberculosis is spread from person to person through the air. When people with lung TB cough, sneeze or spit, they propel the TB germs into the air. A person needs to inhale only a few of these germs to become infected. Tuberculosis is curable and preventable $[1,2]$. A relatively small proportion of people infected with Mycobacterium tuberculosis will go on to develop TB disease; however, the probability of developing TB is much higher among people with immune suppression or compromise. About one-quarter of the world's population has latent TB, which means people have been infected with TB bacteria but are not yet ill with the disease and cannot transmit the disease [2].

Tuberculosis (TB) has existed for millennia and remains a major global health problem. It causes ill-health of approximately 10 million people each year and is one of the top ten causes of death worldwide [3]. According to the Global tuberculosis Report (2017), 10.4 million people have estimated the incidence to have all forms of TB in 2016 while an estimated 1.3 million people died from TB, excluding deaths attributed to TB/HIV in combination. In addition, an estimated $4.1 \%$ of these new TB cases and $19 \%$ of the previously treated cases are believed to harbor drug resistant-TB with an estimated 240,000 deaths annually due to multi-drug resistant tuberculosis (MDR-TB) [3]. Human immunodeficiency virus (HIV) is an infection that attacks the body's immune system, specifically the white blood cells called CD4 cells. HIV destroys these CD4 cells, weakening a person's immunity against infections such as tuberculosis and some cancers. The risk of developing tuberculosis (TB) is estimated to be between 16 and 27 times greater in people living with HIV than among those without HIV. The World Health Organization (WHO) estimates that 4.5 million people are co-infected with HIV and TB globally [1, 2, 4].

Ethiopia is among the 30 highest TB, HIV, and MDRTB burden countries, which accounted for $80 \%$ of all estimated TB cases worldwide. Ethiopia had an annual estimated TB incidence of 207/100,000 populations and a death rate of 33 per 100,000 populations in 2014 [5]. Among the notified TB cases in 2014, 1300 (1.6\%) of new $\mathrm{TB}$ cases and $11.8 \%$ of previously treated $\mathrm{TB}$ cases were drug-resistant [3]. Besides, a drug resistance (DRTB) sentinel report in 2013 showed the MDR-TB prevalence of $2.3 \%$ among new and $17.8 \%$ among previously retreated TB cases in Ethiopia [6] .In the same year, there was notification of 119, 592 new TB cases and enrollment of 597 DR-TB cases [7]. Furthermore, a number of studies have shown the prevalence of Mycobacterium tuberculosis with rifampicin resistance Ethiopia ranged from 4.7$18.3 \%$ [5, 8-11]. Mutations region of 81 base pairs (bp) of the rpoB gene has been found in about $96 \%$ of rifampicin (RMP) resistant Mycobacterium tuberculosis [8, 9].

Ethiopia is implementing a comprehensive TB/Leprosy and $\mathrm{TB} / \mathrm{HIV}$ control programs and has achieved a lot in the past decade. However, In Ethiopia, the case detection rate was very low using smear microscopy in the past, but in its commitment against TB, the Ethiopian government has joined the post-2015 Global TB Strategy called "END TB strategy" which will increase case detection and further reduce the burden of this disease. To achieve these strategies Ethiopia endorsed many advanced technologies concordantly with WHO recommendations, including the implementation of the GeneXpert ${ }^{\mathrm{Tm}}$ MTB/ RIF assay. The assay detects Mycobacterium tuberculosis and rifampicin resistance by identifying mutations using three specific primers and five unique molecular probes through a rapid $(2 \mathrm{~h})$ process with minimal bio-safety requirements and training [12].

Ethiopia is one of the high burden countries, reflected both in its $\mathrm{TB}$ incidence and the estimated rates of MDR-TB [13]. However, there is limited information regarding the trend analysis of $\mathrm{TB}$ and rifampicin resistance in our study area. To date, there are no studies conducted that have reviewed documents systematically to identify the trends in Mycobacterium tuberculosis and rifampicin resistance using GeneXpert ${ }^{\mathrm{Tm}}$ in Adigrat General Hospital. Therefore, this study aimed to determine the trends in Mycobacterium tuberculosis and rifampicin resistance using GeneXpert ${ }^{\text {ti }}$ among TB-presumptive cases at Adigrat General Hospital, Eastern zone of Tigrai, north Ethiopia.

\section{Methods and materials Study design, setting, and time}

A retrospective cross-sectional study design was used to collect the secondary data from June-August, 2019 at the Adigrat General Hospital. The Adigrat General Hospital is found in the Eastern zone of Tigrai, north, Ethiopia at altitude and longitude of $14^{\circ} 16^{\prime} \mathrm{N} 39^{\circ} 27^{\prime} \mathrm{E}$, with an elevation of $2457 \mathrm{~m}(8061 \mathrm{ft})$ above sea level and 560 miles far from capital city Addis Ababa. In the Eastern zone based on the 2007 census conducted by central statistics agency of Ethiopia, has a total population of 755,343 , of $52.4 \%$ women and $19.34 \%$ are urban inhabitants and the majority have low income. There are 2 General Hospital, 5 primary Hospital and 37 health centers. The Adigrat General Hospital is serving as a referral for surrounding health centers and primary hospitals, and teaching center for medical and health science 
students. The hospital has about 120 beds and more than 250 health care providers. Adigrat General Hospital is the only hospital that testing sputum using GeneXpert $^{\mathrm{mu}}$ and treated the MDR-TB for surrounding 7 districts in the Eastern zone of Tigrai.

\section{Inclusion criteria/exclusion criteria}

Those who had completed data in the GeneXpert ${ }^{\mathrm{m}}$ TB registration book were included during the study period specified and those cases with indeterminate and/or invalid results were excluded from the study.

\section{Dependent variable/independent variable}

Mycobacterium tuberculosis result (Positive and Negative) and rifampicin (sensitive and resistance) were dependent variables and sex, residence, age, co-infection, site of presumptive $\mathrm{TB}$, reason for diagnosis and year of diagnosis were independent variables.

\section{Operational definition}

Presumptive-TB: An individual who presents with symptoms or signs suggestive of TB like sweating, coughing more than two weeks, loss of appetite, weight loss and weakness.

Presumptive drug resistance-ТВ case: refers to a person who presents with clinical features suggestive of $\mathrm{TB}$ or diagnosis of active $\mathrm{TB}$ and with either medium - or high- risk of harbor Drug resistant TB.

\section{Sample size}

Retrospectively all presumptive TB patients from a GeneXpert $^{\text {th }}$ TB registration book from January 2015, to December 2018, were included.

\section{Laboratory investigation}

Adigrat General Hospital TB clinic operates under the national TB- and leprosy-control program of Ethiopia, in which the diagnosis of TB is followed by GeneXpert ${ }^{\mathrm{m}}$ MTB/RIF assay for rifampicin resistance. Samples were processed by GeneXpert ${ }^{\text {ti }}$ MTB/ RIF (Cepheid) assay according to the manufacturer's manual.

\section{Data collection and quality of data}

The data were collected retrospectively from the GeneXpert $^{\mathrm{tm}} \mathrm{TB}$ registration book in Adigart General Hospital at the Directly Observed Treatment [short course clinic] (DOTS). Data was collected using a pre-developed checklist and the quality of data was maintained by checking the completeness of necessary information; the obtained data were cross-checked and double entered and re-checked to ensure the quality of data.

\section{Statistical analysis and interpretation}

Data obtained through the checklist and laboratory test results were double entered into the Epi-Info 3.1 software and export to SPSS ${ }^{\text {rn }} 20$. Data analysis was performed using SPSS ${ }^{\text {tux }}$ 20. Descriptive analysis, frequencies, and figures were used to explain the findings. Chi-square analysis was used to correlate categorical variables. Bivariate Logistic regression analysis was conducted primarily to check the association of each independent variable with the dependent variable at $P$ value $<0.2$. Multivariate logistic regression models were employed to analyze specific associations between variables. Odds ratio (OR) and 95\% confidence interval (CIs) were calculated using logistic regression model to measure the strength of an association. In all cases, $p$-values less than 0.05 were considered statistically significant.

\section{Results}

A total of 5944 presumptive TB and drug resistance TB patients was retrospectively included in this study. Among these patients, majorities were male 3455 (58.1\%).The median age of the participants was 40.0 (IQR 26-57), of which the majority were in the age group 30-44 years. Of the total participants, 513 (8.6\%) were HIV positive. Among the presumptive drug resistance TB patients' majority were new case 706 (76.9\%). Diagnosis of Mycobacterium tuberculosis using the GeneXpert $^{\text {tis }}$ have increased between 2015 and 2018 (Table 1).

The overall positivity of Mycobacterium tuberculosis among all forms of presumptive TB patient was 24.3\% (1446/5944). The Mycobacterium tuberculosis positivity rate was highly observed in the age group $30-44$ years, with 420 cases $(26 \%)$. Twenty three percent $(1188 / 5027)$ and $28 \%(258 / 917)$ presumptive of $\mathrm{TB}$ and DR-TB, respectively, were diagnosed with Mycobacterium tuberculosis. MTB/HIV co-infection was observed in $33.3 \%(171 / 513)$ of the involved patients. The trends of the positivity of Mycobacterium tuberculosis almost similar in the first three years but were considerably higher by 2018. Correlation analysis of MTB showed a strong association with age, the reason for diagnosis, site of sample collection and being HIV infected (Table 2).

From the total confirmed of all forms of presumptive TB cases, 9.1\% (132/1446) were resistant to rifampicin, of which $8.7 \%(103 / 1188)$ and $11.2 \%$ (29/ 258) where presumptive $\mathrm{TB}$ and presumptive drug resistance-TB respectively. Of the total confirmed positive cases $8.7 \%(103 / 1385)$ and $11.2 \%(29 / 258)$ were rifampicin resistance of presumptive tuberculosis and presumptive drug resistance tuberculosis patients respectively. Of the total TB-HIV co-infected patients, 
Table 1 Socio-demographic and clinical characteristics of the study subjects in Adigrat General Hospital, Eastern Zone, Tigrai, North Ethiopia

\begin{tabular}{|c|c|c|}
\hline Variables & Frequency & Percentage \\
\hline \multicolumn{3}{|l|}{ Sex } \\
\hline Female & 2489 & 41.9 \\
\hline Male & 3455 & 58.1 \\
\hline \multicolumn{3}{|l|}{ Residence } \\
\hline Urban & 5121 & 86.2 \\
\hline Rural & 823 & 13.8 \\
\hline \multicolumn{3}{|l|}{ Age (Years) } \\
\hline$\leq 14$ & 236 & 4.0 \\
\hline $15-29$ & 1568 & 26.4 \\
\hline $30-44$ & 1620 & 27.3 \\
\hline $45-59$ & 1107 & 18.6 \\
\hline $60-74$ & 1039 & 17.5 \\
\hline $75-89$ & 362 & 6.1 \\
\hline 90 & 12 & .2 \\
\hline \multicolumn{3}{|l|}{ Reason for diagnosis } \\
\hline Presumptive TB & 5027 & 84.6 \\
\hline Presumptive DR TB & 917 & 15.4 \\
\hline \multicolumn{3}{|l|}{ Presumptive DR-TB } \\
\hline New & 706 & 76.9 \\
\hline Relapse & 105 & 11.5 \\
\hline Failure & 87 & 9.5 \\
\hline Lost to follow-up & 19 & 2.1 \\
\hline \multicolumn{3}{|l|}{ Site of presumptive TB } \\
\hline Pulmonary & 5819 & 97.9 \\
\hline Extra-pulmonary & 125 & 2.1 \\
\hline \multicolumn{3}{|l|}{ HIV status } \\
\hline Negative & 4761 & 80.1 \\
\hline Positive & 513 & 8.6 \\
\hline Unknown & 670 & 11.3 \\
\hline \multicolumn{3}{|l|}{ Year of Diagnosis } \\
\hline 2015 & 604 & 10.2 \\
\hline 2016 & 1479 & 24.9 \\
\hline 2017 & 1872 & 31.5 \\
\hline 2018 & 1989 & 33.5 \\
\hline
\end{tabular}

$15.2 \%(26 / 171)$ where rifampicin resistance. The trends of rifampicin-Resistant were seen as a minimum variation from year to year, with the minimum observed in 2018 and the maximum in 2015. The sensitivity and resistance of rifampicin results showed a statistically significant difference with reason of diagnosis and HIV status (Table 3).

The trends of positivity in Mycobacterium tuberculosis and rifampicin resistance were minimum variation between 2015 and 2018. In 2015, Mycobacterium tuberculosis were found in 142/604 (23.5\%) of whom 19/142 (13.4\%) were rifampicin-resistant, but by 2018 Mycobacterium tuberculosis incidence was 540/1989 (27.1\%) of whom $45 / 540(8.3 \%)$ were rifampicin-resistant. In general, rifampicin-resistant in January 2015, 2016, 2017 and till December 31, 2018 were shown 13.4, 8.6, 9.2 and $8.3 \%$ respectively Fig. 1 .

\section{Discussion}

The WHO continues to search for innovative technologies to enhance accurate and reliable laboratory diagnosis of TB to curb Mycobacterium tuberculosis and DR-TB worldwide. However, the emergence of drug-resistant forms of $\mathrm{TB}$, which need more resources to detect, treat, and effectively reduce the burden of disease is a challenging problem. GeneXpert $^{\mathrm{Tm}} \mathrm{MTB} / \mathrm{RIF}$ assay is a new automated real-time Nucleic Acid Amplification Technology that overcomes many of the current operational difficulties in TB diagnosis [14].

TB affects mostly adults in the economically productive age groups with approximately two-thirds of cases estimated to occur among people aged 15-59 years [1].

In the present study, the overall forms of presumptive Mycobacterium tuberculosis positivity rate were $24.3 \%$. Our finding was similar to studies conducted in the Debre Markos Hospital (23.2\%) [15], Gondar Referral Hospital (24.6\%) [16], Gambella (20.0\%) [17], Afar (24.5\%) [18], India (27.6\%) [4], South Africa (26\%) [19], Nigeria (22.9\%) [20] And the WHO report in Africa (25\%) [2]. However, it was lower compared to reports in Jigjiga (65.5\%) [21], Kenya (32.25\%) [22], in eastern Uttar Pradesh (32.9\%) [23] and Congo (79.1\%) [24]. The main difference in these latter findings may show our inclusion of all forms of presumptive tuberculosis while other studies included identified cases of Mycobacterium tuberculosis. In contrast, our finding was higher when compared with studies conducted in Metema and Armacho (5.7\%) [7], Felege Hiwot Referral Hospital, and Debre Tabor Hospital (14.6\%) [25], in three referral hospitals and the regional laboratory in Addis Ababa (15.11\%) [26], other parts of Ethiopia (4.7-10.8\%) [27-29], Nigeria (10.3\%) [30] and India (2.31\%) [31]. The variations might be due to the difference in study design, type and number of participants, and environmental conditions.

The co-infection of TB-HIV in this study was found to be high at $33.3 \%(171 / 513)$. This finding was supported by previous studies conducted in Amhara (27.7\%) [32], Gambella [17], in Ethiopia (29.4\%) [33], and in Central Nigeria (36.3\%) [34]. However, our findings were higher 
Table 2 Trends of positive M. tuberculosis among presumptive TB patients diagnosed in Adigrat General Hospital using GeneXpert ${ }^{\mathrm{TM}}$ MTB/RIF assay

\begin{tabular}{|c|c|c|c|c|c|}
\hline \multirow[t]{2}{*}{ Variables } & \multicolumn{2}{|c|}{ M. tuberculosis result by GeneXpert ${ }^{\mathrm{TM}}$} & \multirow[t]{2}{*}{ Total } & \multirow[t]{2}{*}{ AOR $(95 \% \mathrm{Cl})$} & \multirow[t]{2}{*}{$P$-value } \\
\hline & Detected (\%) & Not-Detected (\%) & & & \\
\hline \multicolumn{6}{|l|}{ Sex } \\
\hline Female & $596(24.0)$ & $1893(76.0)$ & $2489(41.9)$ & a & \\
\hline Male & $850(24.6)$ & $2605(75.4)$ & $3455(58.1)$ & $0.99(0.88-1.12)$ & 0.86 \\
\hline \multicolumn{6}{|l|}{ Residence } \\
\hline Urban & $1266(24.7)$ & $3855(75.3)$ & $5121(86.2)$ & a & \\
\hline Rural & $180(21.9)$ & $643(78.1)$ & $823(13.8)$ & $1.08(0.90-1.29)$ & 0.41 \\
\hline \multicolumn{6}{|l|}{ Age (Years) } \\
\hline$\leq 14$ & 44 (18.6) & $192(81.4)$ & $236(3.9)$ & $2.38(0.299-18.95)$ & 0.41 \\
\hline $15-29$ & $393(25.1)$ & $1175(74.9)$ & $1568(26.4)$ & $3.26(0.42-25.29)$ & 0.26 \\
\hline $30-44$ & $420(26.0)$ & $1200(74.0)$ & $1620(27.3)$ & $3.66(0.47-28.39)$ & 0.22 \\
\hline $45-59$ & $258(23.3)$ & $849(76.7)$ & $1107(18.6)$ & $3.81(0.49-29.67)$ & 0.20 \\
\hline $60-74$ & $235(22.6)$ & $804(77.4)$ & $1039(17.4)$ & $3.64(0.47-28.32)$ & 0.22 \\
\hline $75-89$ & $93(25.7)$ & $269(74.3)$ & $362(6.1)$ & $4.08(0.52-32.05)$ & 0.18 \\
\hline 90 & $3(25.0)$ & $9(75.0)$ & $12(0.3)$ & a & \\
\hline \multicolumn{6}{|l|}{ Reason for diagnosis } \\
\hline Presumptive TB & $1188(23.6)$ & $3839(76.4)$ & $5027(84.6)$ & a & \\
\hline Presumptive DR TB & $258(28.1)$ & $659(71.9)$ & $917(15.4)$ & $1.63(1.40-1.90)$ & $<0.01^{b}$ \\
\hline \multicolumn{6}{|l|}{ Presumptive DR-TB } \\
\hline New & $1385(23.3)$ & $4348(73.1)$ & $5733(96.4)$ & a & \\
\hline Relapse & $31(29.5)$ & $74(70.5)$ & $105(1.8)$ & $2.69(0.73-10.04)$ & 0.14 \\
\hline Failure & $27(31.0)$ & $60(69.0)$ & $87(1.4)$ & $1.68(0.489-5.80)$ & 0.41 \\
\hline Lost to follow- up & $3(15.8)$ & $16(84.2)$ & $19(0.4)$ & $2.79(0.76-10.23)$ & 0.12 \\
\hline \multicolumn{6}{|l|}{ Site of presumptive TB } \\
\hline Pulmonary & $1414(24.3)$ & $4405(75.7)$ & $5819(97.9)$ & a & \\
\hline Extra-pulmonary & $32(25.6)$ & $92(74.4)$ & $125(2.1)$ & $0.70(0.48-1.03)$ & 0.70 \\
\hline \multicolumn{6}{|l|}{ HIV status } \\
\hline Negative & $1128(23.7)$ & $3633(76.3)$ & $4761(80.0)$ & a & \\
\hline Positive & $171(33.3)$ & $342(66.7)$ & $513(8.7)$ & $1.67(1.35-2.07)$ & $<0.01^{\mathrm{b}}$ \\
\hline Unknown & $147(21.9)$ & $523(78.1)$ & $670(11.3)$ & $0.97(0.77-1.21)$ & 0.77 \\
\hline \multicolumn{6}{|l|}{ Year of Diagnosis } \\
\hline 2015 & $142(23.5)$ & $462(76.5)$ & $604(10.2)$ & $0.75(0.61-0.93)$ & 0.08 \\
\hline 2016 & 339 (22.9) & $1140(77.1)$ & 1479 (24.9) & $0.63(0.54-0.74)$ & $<0.01$ \\
\hline 2017 & $425(22.7)$ & 1447 (77.3) & $1872(31.5)$ & $0.65(0.56-0.75)$ & $<0.01$ \\
\hline 2018 & $540(27.1)$ & 1449 (72.9) & 1989 (33.4) & a & \\
\hline
\end{tabular}

${ }^{a}$-Reference category M. tuberculosis- Mycobacterium tuberculosis, DR TB -drug resistant tuberculosis and AOR-Adjusted odd ratio, ${ }^{b}$ Significantly associated

than studies conducted in the Debre Markos Referral Hospital (16.6\%) [15], different studies across Ethiopia (20.3-24.2\%) [16, 35-38], and a WHO estimation for Ethiopia of $14 \%(9.6-19 \%)$ [2]. Conversely, the findings were lower than studies conducted in the Felege Hiwot Referral Hospital and Debre Tabor Hospital (41.9\%) [25], Zambia (98.3\%) [39], and South Africa (>70\%) [40]. The possible explanations for this difference could be reflect policy recommendations for which HIV infected patients, as an eligible group, are more likely to be tested using GeneXpert ${ }^{\mathrm{Tm}}$.

In this study, Mycobacterium tuberculosis was prevalent in all ages, but have seriously hit the age group of 30-44 years with $26.0 \%$ and of whom $34 / 420$ (8.1\%) were rifampicin resistant. The positivity finding was in line with studies conducted in Gondar (29.8\%) 
Table 3 Multivariable analysis of rifampicin-resistant among the total Mycobacterium tuberculosis cases using GeneXpert ${ }^{\mathrm{TM}}$ MTB/RIF assay, in Adigrat General Hospital

\begin{tabular}{|c|c|c|c|c|c|}
\hline \multirow[t]{2}{*}{ Variables } & \multicolumn{2}{|l|}{ Pattern of RIF } & \multirow[t]{2}{*}{ Total N (\%) } & \multirow[t]{2}{*}{ AOR $(95 \% \mathrm{Cl})$} & \multirow[t]{2}{*}{$P$-value } \\
\hline & Sensitive N (\%) & Resistant N (\%) & & & \\
\hline \multicolumn{6}{|l|}{$\overline{\text { Sex }}$} \\
\hline Female & $535(89.8)$ & $61(10.2)$ & $596(41.2)$ & a & \\
\hline Male & 779 (91.6) & $71(8.4)$ & $850(58.8)$ & $0.74(0.5-1.09)$ & 0.13 \\
\hline \multicolumn{6}{|l|}{ Residence } \\
\hline Urban & $1151(90.9)$ & $115(9.1)$ & $1266(87.5)$ & a & \\
\hline Rural & $163(90.6)$ & $17(9.4)$ & $180(12.5)$ & $1.10(0.61-1.99)$ & 0.74 \\
\hline \multicolumn{6}{|l|}{ Age (Years) } \\
\hline$\leq 14$ & $41(93.2)$ & $3(6.8)$ & $44(3.0)$ & a & \\
\hline $15-29$ & $376(95.7)$ & $17(4.3)$ & $393(27.2)$ & $1.12(0.37-3.36)$ & 0.84 \\
\hline $30-44$ & $386(91.9)$ & $34(8.1)$ & $420(29.1)$ & $0.52(0.16-1.53)$ & 0.23 \\
\hline $45-59$ & $225(87.2)$ & $33(12.8)$ & $258(17.8)$ & $0.54(0.18-1.62)$ & 0.27 \\
\hline $60-74$ & $205(87.2)$ & $30(12.8)$ & $235(16.3)$ & $0.53(0.17-1.60)$ & 0.26 \\
\hline $75-89$ & $78(83.9)$ & $15(16.1)$ & $93(6.4)$ & $1.48(0.46-4.74)$ & 0.51 \\
\hline$\geq 90$ & $3(100)$ & 0 & $3(0.2)$ & & \\
\hline \multicolumn{6}{|l|}{ Reason for diagnosis } \\
\hline Presumptive TB & $1085(91.3)$ & $103(8.7)$ & $1188(82.1)$ & $a$ & \\
\hline Presumptive DR TB & $229(88.8)$ & $29(11.2)$ & $258(17.9)$ & $8.92(5.81-13.69)$ & $<0.01^{\mathrm{b}}$ \\
\hline \multicolumn{6}{|l|}{ Presumptive DR-TB } \\
\hline New & $1256(90.7)$ & $129(9.3)$ & $1385(95.7)$ & a & \\
\hline Relapse & $30(96.8)$ & $1(3.2)$ & $31(2.2)$ & $0.32(0.02-4.71)$ & 0.41 \\
\hline Failure & $26(96.3)$ & $1(3.7)$ & $27(1.9)$ & $0.16(0.01-1.85)$ & 0.14 \\
\hline Lost to follow-up & $2(66.7)$ & $1(33.3)$ & $3(0.2)$ & $0.16(0.01-2.49)$ & 0.19 \\
\hline \multicolumn{6}{|l|}{ Site of presumptive TB } \\
\hline Pulmonary & $1283(90.7)$ & $131(9.3)$ & 1414 (97.8) & a & \\
\hline Extra-pulmonary & $31(96.8)$ & $1(3.2)$ & $32(2.2)$ & $0.62(0.22-1.76)$ & 0.37 \\
\hline \multicolumn{6}{|l|}{ HIV status } \\
\hline Negative & $1036(91.8)$ & $92(8.2)$ & $1128(78.1)$ & a & . \\
\hline Positive & $145(84.8)$ & $26(15.2)$ & $171(11.8)$ & $1.97(1.13-3.44)$ & $0.02^{b}$ \\
\hline Unknown & $133(90.5)$ & $14(9.5)$ & $147(10.1)$ & $0.88(0.45-1.72)$ & 0.72 \\
\hline \multicolumn{6}{|l|}{ Year of Diagnosis } \\
\hline 2015 & $123(86.7)$ & 19 (13.4) & $142(9.8)$ & $2.24(1.19-4.24)$ & 0.01 \\
\hline 2016 & $310(91.4)$ & $29(8.6)$ & $339(23.5)$ & $0.91(0.53-1.55)$ & 0.72 \\
\hline 2017 & $386(90.8)$ & $39(9.2)$ & $425(29.4)$ & $1.20(0.74-1.96)$ & 0.47 \\
\hline 2018 & $495(91.7)$ & $45(8.3)$ & $540(37.3)$ & a & \\
\hline
\end{tabular}

${ }^{a}$-Reference category, RIF -rifampicin resistant, DR TB -drug resistant tuberculosis, M. tuberculosis-Mycobacterium tuberculosis and AOR-Adjusted odd ratio, ${ }^{\mathrm{b}}$ Significantly associated

[16], different studies in Ethiopia [27-29, 41], WHO reports 2017 [2] and Agaro Teaching Health Center in southwestern Ethiopia [42]. However, contrary findings with several studies in a different part of Nigeria and Zambia [22, 30, 39] which had lower prevalence, but higher than a study conducted in eastern Uttar Pradesh (40\%) [23].
In the present study, the percentage of Mycobacterium tuberculosis positivity significantly higher in presumptive TB patients (20.0\%) compared to presumptive drug resistance $(4.3 \%)$ with $(P<0.00)$. This finding was comparable to studies conducted in Afar (20.9) [18], Debre Markos Referral Hospital (15.1\%) [15] and Gambella (19.6\%) [17]. However, it is much lower than studies 


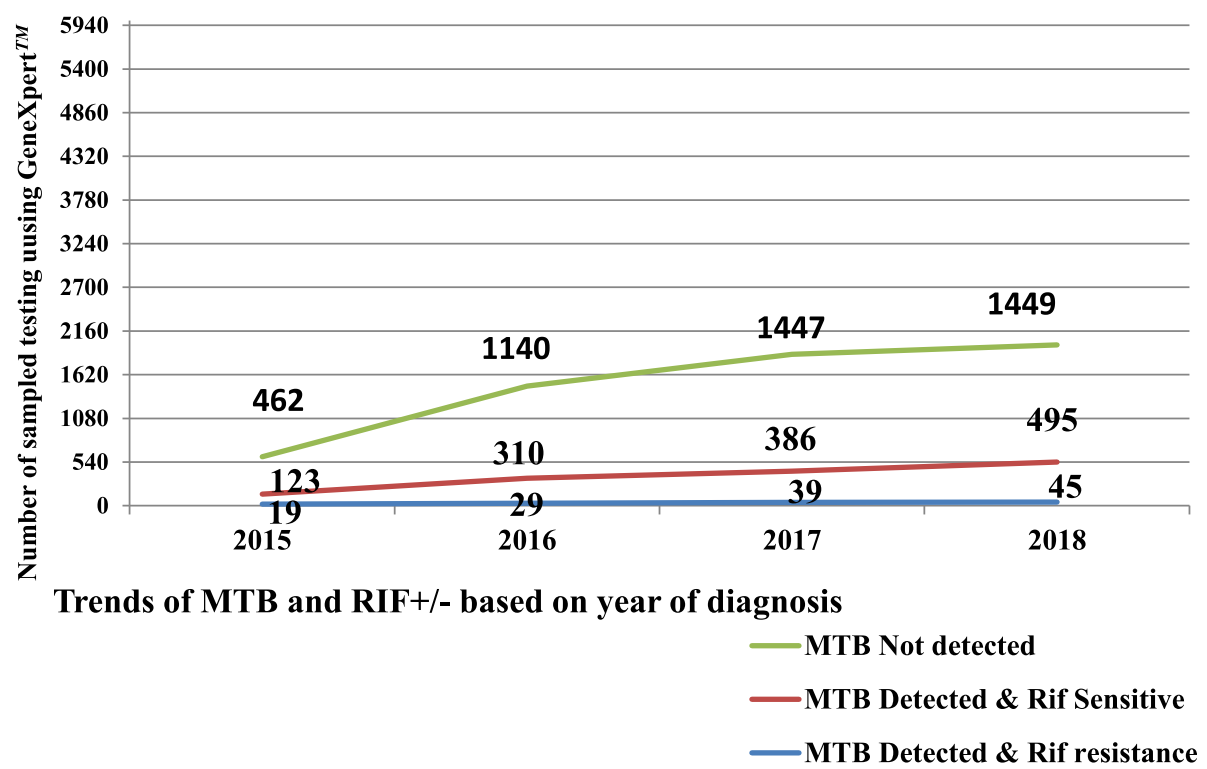

Fig. 1 Trends of Mycobacterium tuberculosis and rifampicin resistant in Adigrat General Hospital, eastern zone of Tigrai, Northern Ethiopia

conducted in Felege Hiwot Referral Hospital and Debre Tabor Hospital (54.8) [25], Gondar (25.2\%) [16] and Zimbabwe (37.1\%) [43]. The discrepancies might be due to our inclusion of all presumptive TB cases, and a high number of participants.

According to our study, we found 132 (9.1\%) of rifampicin-resistant cases among confirmed TB cases. This result is comparable with studies conducted in Debre Markos Referral Hospital (10.3\%) [15], Felege Hiwot Referral Hospital and Debre Tabor Hospital (9.3\%) [25], Addis Ababa (9.9\%) [26] and India (10.5\%) [44]. Our finds are higher than studies conducted on northwest, east and south parts of Ethiopia (2.9-5.7\%) [7, 17, 23, 26, 37, 38, 45, 46], Nigeria (2.9\%) [30] and Zambia (5.9\%) [39]. The possible explanation for these variations could be related to our retrospective approach spanning four years, or differences in study designs. However, our incidence was lower than for studies conducted in Gondar 15.8\% [16],other parts of Ethiopia (11.539.4) [45, 47, 48],Congo (42.2\%) [24] and China $(17.6-26.3 \%)[6,49]$.

\section{Limitation of the study}

As we collected retrospective data from the GeneXpert ${ }^{\mathrm{Tm}}$ TB registration book, we encountered data missing and incompleteness. Variables included for associated factors were also limited.

\section{Conclusion}

In our study, the overall trends of Mycobacterium tuberculosis and rifampicin resistance were found to be high and with minimum variation each year. Rifampicin resistance is more common in patients with HIV and presumptive drug resistance tuberculosis individuals. Therefore, maximizing early detection of drug-resistant and strengthening tuberculosis infection control activities are recommended to reduce the burden of this contagious and potentially deadly disease.

\section{Abbreviations}

ADU: Adigrat University; AGHL: Adigrat General Hospital Laboratory; DNA: Deoxyribonucleic Acid; DOTS: Directly Observed Treatment, short course; HIV: Human Immunodeficiency Virus; M. tuberculosis: Mycobacterium tuberculosis; MDR-TB: Multidrug Resistance tuberculosis; RIF: Rifampicin; RNA: Ribonucleic Acid; TB: tuberculosis; WHO: World Health Organization; XDR TB: Extensively drug resistant tuberculosis

\section{Acknowledgements}

First of all we would like to thank the Research Approving and Ethics Committee, which provided approval to conduct this research and Adigrat General Hospital laboratory for documented information about GeneXpert ${ }^{\mathrm{T}}$. We also wish to express our sincere thanks and appreciation to Dr. Chernet Gebre, Medical Director, and Mr. Tedros Hadera, Chief Executive Officer of the Adigart General Hospital and all Adigrat laboratory staff for their supporting and communication in accessing necessary documents. In the last but not the least we would like to thank for Professor Pammla Petrucka, from university of Saskatchewan, Canada for revising this manuscript and English language editing.

\section{Authors' contributions}

GK conceived and designed the study, performed the analysis, interpreted data, and drafted the manuscript. BH assisted with the design, proposal preparation, data collection, performed analysis and interpretation of data, and critically prepared and reviewed the manuscript. All authors read and approved the submitted version of the manuscript.

\section{Funding}

Not applicable.

Availability of data and materials

The findings of this study are generated from the data collected and analyzed based on the stated methods and materials. All the data are found in the manuscript and there are no supplementary files. The original data 
supporting this finding will be available upon request through the corresponding author.

\section{Ethics approval and consent to participate}

This study was reviewed and approved by research and community service Ethical Review Board (RERB) of Adigart University, College of Medicine and Health Sciences and after discussion of the purpose and aim of the study permission was obtained from Adigrat General Hospital Chief Executive Officer and Laboratory Head to access the GeneXpert ${ }^{\mathrm{TM}}$ TB registration book. Written informed consent was not sought from the study participants as secondary data were used. Confidentiality of the results was maintained through the anonymous data set and not communicated for other purposes.

\section{Consent for publication}

Not applicable.

\section{Competing interests}

The authors declare that they have no competing interests.

\section{Author details}

'Department of Medical Laboratory, College of Medicine and Health Sciences, Adigrat University, P. O. Box 50, Adigrat, Ethiopia. ${ }^{2}$ Department of Medical Laboratory, Adigrat General Hospital, Adigrat, Ethiopia.

Received: 18 January 2020 Accepted: 27 July 2020

Published online: 28 August 2020

\section{References}

1. Centers of disase control and prevantion (CDC) .Basic TB facts. March 10,2016.Avalaible on https://www.cdc.gov/tb/topic/basics/glossary.htm. Accessed 5 May 2019.

2. World Health Organization. Tuberculosis fact sheet 2019. Avaliable on https://www.who.int/news-room/fact sheets/detail/. Accessed 5 May 2019.

3. World Health Organization. Resistant TB ( MDR / RR-TB):The global TB situation. 2017;34.Available from:https://www.who.int/tb/areas-of-work/drugresistant-tb/MDR-TB. Accessed 5 May 2019.

4. Alvarez-Uria G, Azcona JM, Midde M, Naik PK, Reddy S, Reddy R. Rapid diagnosis of pulmonary and extrapulmonary tuberculosis in HIV-infected patients. Comparison of LED fluorescent microscopy and the GeneXpert MTB/RIF Assay in a district hospital in India. Tuberc Res Treat. 2012:1-4 Available from: http://www.hindawi.com/journals/trt/2012/932862/. Accessed 17 Apr 2019.

5. Mekonnen F, Tessema B, Moges F, Gelaw A, Eshetie S, Kumera G. Multidrug resistant tuberculosis: prevalence and risk factors in the districts of Metema and west Armachiho, Northwest Ethiopia. BMC Infect Dis. 2015;15(1):2-7.

6. Yang $Y$, Zhou $C$, Shi L, Meng $H$, Yan H. Prevalence and characterization of drug-resistant tuberculosis in a local hospital of Northeast China. Int J Infect Dis. 2014:22:83-6.

7. Federal Democratic Republic of Ethiopia Ministry of Health; National Comprehensive Tuberculosis, Leprosy and TB/HIV Training Manual for Health Care Workers, 2012. Available from: https://www.slideshare.net/ suleymanfantahun/new-ethiopian-tb-guildline-november-2012. Accessed 10 May 2019.

8. Nigus DM, Lingerew WM, Beyene BA, Tamiru AA, Lemma MT, Melaku MY. Prevalence of multi drug resistant tuberculosis among presumptive multi drug resistant tuberculosis cases in Amhara National Regional State, Ethiopia. Mycobact Dis. 2014;4(3):2-7.

9. Getahun M, Ameni G, Kebede A, Yaregal Z, Hailu E, Medihn G, et al. Molecular typing and drug sensitivity testing of mycobacterium tuberculosis isolated from a community-based survey in Ethiopia. BMC Public Health. 2015;15(1):1-7.

10. Ethiopian Health and Nutration Research Institute. First Ethiopian National Population Based Tuberculosis Prevalence survey. Ethiopian Public health institute2011; Available from:https://www.ephi.gov.et/images/downloads/ Tuberculosis\%20Prevalence\%20Survey.pd. Accessed 17 Apr 2019.

11. Sinshaw W, Kebede A, Bitew A, et al. Prevalence of tuberculosis, multidrug resistant tuberculosis and associated risk factors among smear negative presumptive pulmonary tuberculosis patients in Addis Ababa, Ethiopia. BMC Infect Dis. 2019;19:641. https://doi.org/10.1186/s12879-019-4241-7.

12. Federal Democratic Republic of Ethiopia ministry of health. Guidelines for the programmatic management of drug-resistant tuberculosis in Ethiopia. 2013;2nd edition. Avaliable on the www.medbox.org. Accessed 17 Apr 2019.

13. Girum T, Muktar E, Lentiro K, Wondiye H, Shewangizaw M. Epidemiology of multidrug-resistant tuberculosis (MDR-TB) in Ethiopia: a systematic review and meta-analysis of the prevalence, determinants and treatment outcome. Trop Dis Travel Med Vaccines. 2018;4:-5. https://doi.org/10.1186/s40794-0180065-5 PMID: 29942536; PMCID: PMC6000958.

14. World Health organaztion. Automated Real-time Nucleic Acid Amplification Technology for Rapid and Simultaneous Detection of Tuberculosis and rifampicin resistance: In: MTB/RIF, WHO Policy Xpert,Xpert MTB/RIF system WHO/HTM/TB/ 20114 Geneva; 2011. Available on the WHO web site (www.who.int). Accessed 5 May 2019.

15. Mulu W, Abera B, Yimer M, Hailu T, Ayele H, Abate D. Rifampicin-resistance pattern of mycobacterium tuberculosis and associated factors among presumptive tuberculosis patients referred to Debre Markos referral hospital, Ethiopia: a cross-sectional study. BMC Res Notes. 2017;10(1):1-8.

16. Jaleta KN, Gizachew M, Gelaw B, Tesfa H, Getaneh A, Biadgo B. Rifampicinresistant mycobacterium tuberculosis among tuberculosis-presumptive cases at University of Gondar Hospital, Northwest Ethiopia. Infect Drug Resist. 2017;10:185-92.

17. Ejeta E, Beyene G, Bonsa Z, Abebe G. Xpert MTB / RIF assay for the diagnosis of Mycobacterium tuberculosis and rifampicin resistance in high Human Immuno deficiency Virus setting in Gambella regional state, southwest Ethiopia. J Clin Tuberc Other Mycobact Dis. 2018; 12 (May): 1420. https://doi.org/10.1016/j.jctube.2018.06.002.

18. Gebrehiwet GB, Kahsay AG, Welekidan $L N$, et al. Rifampicin resistant tuberculosis in presumptive pulmonary tuberculosis cases in Dubti hospital, Afar, Ethiopia. J Infect Dev Ctries. 2019;13(1):21-7. https://doi.org/10.3855/ jidc. 10462.

19. Cox HS, Mbhele S, Mohess N, Whitelaw A, Muller O, Zemanay W, et al. Impact of Xpert MTB/RIF for TB diagnosis in a primary care clinic with high TB and HIV prevalence in South Africa: a pragmatic randomizedtrial. PLoS Med. 2014;11(11):1-12

20. IkuabePo, Ebuenyi ID Prevalence of Rifampicin resistance by automated GeneXpert Rifampicin assay in patients with pulmonary tuberculosis in Yenagoa, Nigeria. Pan Afr MED J [Internet]. 2018;(29):204. Available from: doi: https://doi.org/10.11604/Pamj.2018.29.204.14579.

21. Mesfin W, Mulualem A, Mubarek A, et al. Use of Xpert MTB/RIF for the identification of TB and drug resistance among smear-negative and retreatment cases in rural areas of Ethiopia. Open Microbiol J. 2019;13:188-92. Available from https://openmicrobiologyjournal.com. https://doi.org/10. 2174/1874285801913010188

22. Muia PK, Ngugi MP, Mburu DN. Performance of GeneXpert Assay in detecting pulmonary tuberculosis and Rifampicin resistance in Patients Attending Kitui County Hospital, Kenya. J Trop Dis. 2017;05(04). https://doi. org/10.4172/2329-891X.1000246.

23. Gautam PB, Mishra A, Kumar S. Prevalence of Rifampicin resistant Mycobacterium tuberculosis and associated factors among presumptive tuberculosis patients in eastern Uttar Pradesh. Int J Community Med Public Health. 2018;5(6):2271-6. https://doi.org/10.18203/2394-6040. ijcmph20182039.

24. Farra A, Manirakiza A, Yambiyo BM, et al. Surveillance of rifampicin resistance with GeneXpert MTB/RIF in the National Reference Laboratory for tuberculosis at the Institut Pasteur in Bangui, 2015-2017. Open Forum Infect Dis. 2019;6(3):ofz075. https://doi.org/10.1093/ofid/ofz075.

25. Derbie A, Worku S, Mekonnen D, Mezgebu Y, Teshager A, Birhan A, et al. GeneXpert ${ }^{\mathrm{TM}}$ MTB/RIF assay for the diagnosis of mycobacterium tuberculosis and its rifampicin resistance at Felege Hiwot referral hospital and Debre Tabor hospitals, Northwest Ethiopia. Ethiopia J Heal Dev. 2016;30(2):60-5 Avaliable on https://www.ajol.info/index.php/ejhd/article/view/167744/157153.

26. Arega B, Menbere F, Getachew Y. Prevalence of rifampicin resistant Mycobacterium tuberculosis among presumptive tuberculosis patients in selected governmental hospitals in Addis Ababa, Ethiopia. BMC Infect Dis. 2019;19:307.

27. Deribew A, Negussu N, Melaku Z, Deribe K. Investigation outcomes of tuberculosis suspects in the health centers of Addis Ababa, Ethiopia. PLoS One. 2011;6(4):2-6

28. Gebre D, Mimano LN. Prevalence of smear positive pulmonary tuberculosis among patients attending Seka health center, Jimma, Oromia region, Ethiopia. East Afr J Public Heal. 2010;3(7):268-73. https://doi.org/10.4314/ eajph.v7i3.64739. 
29. Yohanes A, Abera S, Ali S. Smear positive pulmonary tuberculosis among suspected patients attending metehara sugar factory hospital; eastern Ethiopia. Afr Health Sci. 2012;12(3):325-30. https://doi.org/10. 4314/ahs.v12i3.12

30. Azuonwu O, Ihua N, Kpomasiruchi W. Molecular detection of mycobacterium tuberculosis (MTB) and rifampicin resistant strain among subjects accessing health care at the Federal Medical Centre, Yenegoa, Bayelsa state; Nigeria. iMedPub J. 2017;08(03):1-7.

31. Sharma S, Madan M, Agrawal C, Asthana A. Genotype MTBDR plus assay for molecular detection of Rifampicin and isoniazid resistance in Mycobacterium tuberculosis. Indian J Pathol Microbiol. 2014;57(3):423.

32. Mitku AA, Dessie ZG, Muluneh EK, Workie DL. Prevalence and associated factors of TB/HIV co-infection among HIV infected patients in Amhara region, Ethiopia. Afr Health Sci. 2016;16(2):588-95.

33. Ali SA, Mavundla TR, Fantu R, et al. Outcomes of TB treatment in HIV coinfected TB patients in Ethiopia: a cross-sectional analytic study. BMC Infect Dis. 2016;16:640. https://doi.org/10.1186/s12879-016-1967-3.

34. Gyar SD, Dauda E, Reuben CR. Prevalence of tuberculosis in HIV/AIDS patients in Lafia, Central Nigeria. IntJ Curr Microbiol AppSci. 2014;3(6):831-8 Avalaible on http://www.ijcmas.com.

35. Ahmed A, Mekonnen D, Shiferaw AM, et al. Incidence and determinants of tuberculosis infection among adult patients with HIV attending HIV care in north-East Ethiopia: a retrospective cohort study. BMJ Open. 2018;8:e016961. https://doi.org/10.1136/bmjopen-2017-016961.

36. Mohammed S, Gebremariam TT. Tuberculosis among HIV-positive patients at Butajira hospital, south-Central Ethiopia. Int J Pharmacol Sci Res. 2015; 6(12):1406-11.

37. Tarekegne $D$, Jemal M, Atanaw $T$, et al. Prevalence of human immunodeficiency virus infection in a cohort of tuberculosis patients at Metema Hospital, Northwest Ethiopia: a 3 years retrospective study. BMC Res Notes. 2016;9:192. https://doi.org/10.1186/s13104-016-2004-8.

38. Worku S, Derbie A, Mekonnen D, Biadglegne F. Treatment outcomes of tuberculosis patients under directly observed treatment, short-course at Debre Tabor General Hospital,northwest Ethiopia. Infect Dis Poverty. 2018; 7(1):16. https://doi.org/10.1186/s40249-018-0395-6.

39. Masenga SK, Mubila H, Hamooya BM. Rifampicin resistance in mycobacterium tuberculosis patients using the GeneXpert at the Livingstone central hospital. BMC Infect Dis. 2017;17(1):1-4.

40. Coovadia YM, Mahomed S, Pillay M, Werner L, Mlisana K. Rifampicin monoresistance in mycobacterium tuberculosis in KwaZulu-Natal, South Africa. PLoS One. 2013;8(11):8-12

41. Abdella K, Abdissa K, Kebede W, Abebe G. Drug resistance patterns of mycobacterium tuberculosis complex and associated factors among treatment cases around Jimma, Southwest Ethiopia. BMC Public Health. 2015;15(1):1-7.

42. Ali H, Zeynudin A, Mekonnen A, Abera S, Ali S. Smear Posetive pulmonary tuberculosis (PTB) prevalence amongst patients at Agaro teaching health center, south West Ethiopia. Ethiop J Health Sci. 2012; 22(1):71-6.

43. Makamure B, Mhaka J, Makumbirofa S, Mutetwa R, Mupfumi L, Mason P, et al. Microscopic-observation drug-susceptibility assay for the diagnosis of drug-resistant tuberculosis in Harare Zimbabwe. PLoS One. 2013;8(2): e55872.

44. Gupta A, Mathuria JP, Singh SK, Gulati AK, Anupurba S. Antitubercular drug resistance in four health care facilities in North India. J Health Popul Nutr. 2011;29(6):583-92.

45. Seyoum B, Demissie M, Worku A, Bekele S, Aseffa A. Prevalence and drug resistance patterns of mycobacterium tuberculosis among new smear positive pulmonary tuberculosis patients in eastern Ethiopia. Tuberc Res Treat. 2014;2014:1-7.

46. Mekonnen D, Admassu A, Mulu W, Amor A, Benito A, Gelaye W, et al. Multidrug-resistant and heteroresistant mycobacterium tuberculosis and associated gene mutations in Ethiopia. Int J Infect Dis. 2015;39: 34-8.

47. Mesfin EA, Beyene D, Tesfaye A, Admasu A, Addise D, Amare M, et al. Drugresistance patterns of mycobacterium tuberculosis strains and associated risk factors among multi drug-resistant tuberculosis suspected patients from Ethiopia. PLoS One. 2018:13(6):1-16.

48. Abdella K, Abdissa K, Kebede W, Abebe G. Drug resistance patterns of Mycobacterium tuberculosis complex and associated factors among retreatment cases around Jimma, Southwest Ethiopia. BMC Public Health. 2015;15:599. https://doi.org/10.1186/s12889-015-1955-3.

49. Song W, Li Y, Ma X, Liu J, Tao N, Liu Y, et al. Primary drug resistance of Mycobacterium tuberculosis in Shandong , China , 2004-2018. Respir Res. 2019;20(223):1-12

\section{Publisher's Note}

Springer Nature remains neutral with regard to jurisdictional claims in published maps and institutional affiliations.
Ready to submit your research? Choose BMC and benefit from:

- fast, convenient online submission

- thorough peer review by experienced researchers in your field

- rapid publication on acceptance

- support for research data, including large and complex data types

- gold Open Access which fosters wider collaboration and increased citations

- maximum visibility for your research: over $100 \mathrm{M}$ website views per year

At BMC, research is always in progress.

Learn more biomedcentral.com/submissions 